\title{
Relative contribution of humoral and metastatic factors to the pathogenesis of hypercalcaemia in malignancy
}

\author{
S H RALSTON, I FOGELMAN, M D GARDINER, I T BOYLE
}

\begin{abstract}
Some relations between metastatic bone diseäse and calcium homoeostasis were determined in a consecutive series of 81 patients with solid malignant tumours attending for radionuclide bone scans. Biochemical evaluation showed that bone resorption from metastatic disease was generally not enough to account for hypercalcaemia. While skeletal metastases were present in about half of the patients who developed hypercalcaemia, biochemical indices of bone resorption in these subjects were greatly increased and disproportionate to the extent of metastatic disease detected by the bone scans. Furthermore, a reduced renal phosphate threshold and increased tubular calcium reabsorption were generally observed in hypercalcaemic patients when compared with their normocalcaemic counterparts.

These findings suggest that in most cases malignancy associated hypercalcaemia may be caused by the release of a humoral factor by tumour tissue which exhibits "parathyroid-hormone-like" activity with regard to bone resorption, renal phosphate threshold, and renal calcium handling. It may be postulated that this putative humoral mediator predisposes to hypercalcaemia both by stimulating generalised osteolysis and in most cases also by impairing the renal excretion of the resultant increase in filtered calcium load.

While hypercalcaemia may arise as a result of metastatic bone disease alone, these data indicate that this may be the exception rather than the rule. Hence the term "metastatic hypercalcaemia" should probably be reserved for patients with extensive skeletal tumour disease in whom biochemical evaluation fails to yield evidence of an underlying humorally mediated cause.
\end{abstract}

\section{Introduction}

In patients with hypercalcaemia of malignancy two pathogenic mechanisms are commonly implicated. In those with bone metastases hypercalcaemia is attributed to local release of skeletal calcium by invading tumour at a rate exceeding the renal capacity for its excretion. ${ }^{1-4}$ Alternatively, hypercalcaemia may be caused by a humoral mediator, as yet undefined, whose mechanisms of action in some respects resemble those of parathyroid hormone, ${ }^{5}$ or very rarely the ectopic production of parathyroid hormone itself may be detected. ${ }^{4}$

Hitherto a humoral aetiology of hypercalcaemia has been considered uncommon, ${ }^{4}$ and is usually invoked only when evidence of skeletal metastases is lacking. ${ }^{6}$ 7 Conversely, finding skeletal metastases is conventionally thought to provide reason

\footnotetext{
Departments of Medicine and Biochemistry, Royal Infirmary, Glasgow

S H RALSTON, MB, MRCP, registrar in medicine

I FOGELMAN, MD, MRCP, senior registrar in medicine

$M$ D GARDINER, FRSC, principal biochemist

I T BOYLE, BSC, FRCP, reader in medicine

Correspondence to: Dr S H Ralston, University Department of Medicine, Royal Infirmary, Glasgow G31 2ER.
}

enough for hypercalcaemia without the need to look for an additional humoral component. ${ }^{4}$ Recent studies, however, have questioned the causative role of skeletal metastases in the pathogenesis of hypercalcaemia associated with malignancy ${ }^{8}$ and have emphasised the greater importance of humoral factors, even in patients with tumour deposits in bone. ${ }^{5}$

We have therefore reassessed the relative contributions of humoral and metastatic factors to alterations in calcium metabolism in a consecutive series of patients with malignancy.

\section{Patients and methods}

We studied 81 patients with proved malignant disease attending the nuclear medicine department of Glasgow Royal Infirmary for routine bone scanning. They comprised 27 subjects with hypercalcaemia of malignancy presenting consecutively over 18 months (adjusted serum calcium concentration greater than $2.7 \mathrm{mmol} / \mathrm{l}$ $(10.8 \mathrm{mg} / 100 \mathrm{ml}))$ and 54 normocalcaemic patients presenting consecutively over three months. Seven patients with breast carcinoma had been treated with tamoxifen (three hypercalcaemic, four normocalcaemic) and three with prostatic carcinoma had received stilboestrol (one hypercalcaemic, two normocalcaemic) for siveral months before the study. These drugs were not considered to have exerted a major influence on the variables assessed, however, as four patients had developed hypercalcaemia despite receiving them. Furthermore, biochemical measurements in the remaining six normocalcaemic subjects were not significantly different from those of their counterparts with similar bone scan appearances who had not received hormone treatment. No patient had received other anticancer chemotherapy, antihypercalcaemic agents (except fluid), or diuretics at the time of or immediately before study. Patients with myeloma and other haematological malignancies were excluded.

Hypercalcaemic patients underwent standard rehydration with intravenous $0.9 \%$ sodium chloride solution $3 \mathrm{l}$ daily given for 48 hours or until a daily urine output of greater than $2500 \mathrm{ml}$ was achieved. Biochemical assessment was then performed during the continued infusion of isotonic saline $2 \mathrm{l}$ daily. This method of rehydration is adequate in replacing the sodium deficit observed in hypercalcaemia of malignancy. ${ }^{39}$

In all patients biochemical analyses were performed on fasting blood and urine samples, generally obtained on the morning of the bone scan. All biochemical measurements were made using standard techniques. Serum total calcium concentration was adjusted to a reference albumin value of $47 \mathrm{~g} / 1$ by a method that correlates well with measured ionised calcium values over a wide range of albumin concentrations. ${ }^{10}$ All serum calcium values mentioned below were so derived after adjustment for albumin concentration. Urinary excretion of calcium was expressed both as the molar ratio of calcium to creatinine $(\mathrm{Ca}: \mathrm{Cr} ; \mathrm{mmol}: \mathrm{mmol})$ and as $\mathrm{Ca}_{\mathrm{E}}$, calculated as: $\mathrm{Ca}_{\mathrm{E}}=$ molar ratio of urinary calcium to urinary creatinine multiplied by serum creatinine concentration and expressed as $\mu \mathrm{mol} / 1$ of glomerular filtrate. ${ }^{11}$ Renal tubular phosphate threshold $\left(\mathrm{TmPO}_{4}\right)$ was calculated from the nomogram of Bijvoet. ${ }^{12}$ Urinary hydroxyproline excretion was determined using the Hypronosticon method (Organon Ltd).

Hydroxyproline excretion was then expressed as the molar ratio of hydroxyproline to creatinine (OHP:Cr;mmol:mmol). Immunoreactive parathyroid hormone was measured with a double antibody radioimmunoassay which recognises both $\mathrm{N}$ and $\mathrm{C}$ terminal ends of the hormone molecule. Bone scans were performed three hours after the intravenous injection of $530 \mathrm{MBq}(14.3 \mathrm{mCi}){ }^{99} \mathrm{mTc}$ labelled methylene diphosphonate. Scans were assessed blindly by one of us (IF) as "normal," "light skeletal tumour load" (fewer than six metastases), and "heavy skeletal tumour load" (over six metastases). In seven patients (six normocalcaemic, one hypercalcaemic) abnormalities of doubtful relevance were seen in the scan, which were thought to represent degenerative disease. 
Clinical and biochemical details in patients with malignancy. Biochemical values are medians (range in parentheses)

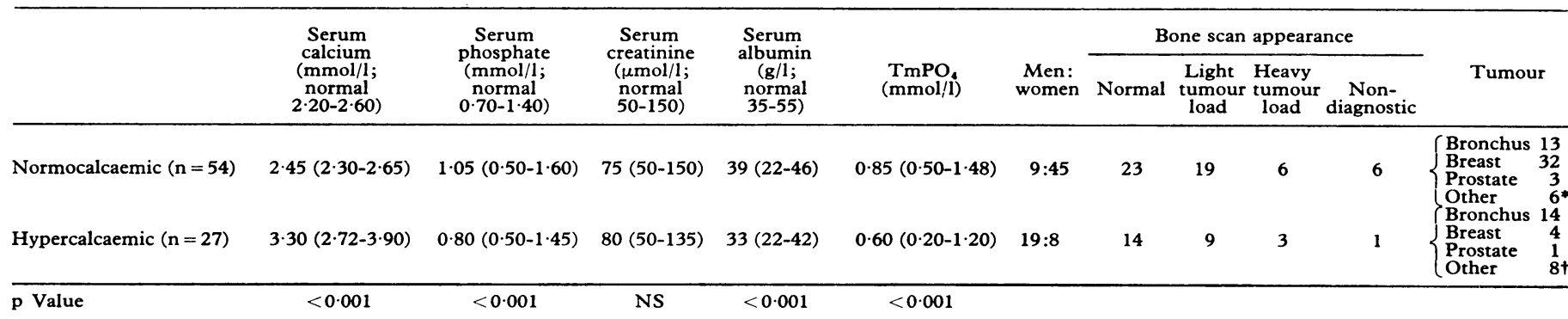

*Adenocarcinoma of: gastrointestinal tract 4, bladder 1 , thyroid 1.

+Nasopharynx 2, genitourinary tract 2 , pancreas 1 , oesophagus 1 , cholangiocarcinoma 2 .
Conversion: SI to traditional units-Calcium: $1.0 \mathrm{mmol} / 1 \approx 4.0 \mathrm{mg} / 100 \mathrm{ml}$. Phosphate: $1.0 \mathrm{mmol} / 1 \approx 3.0 \mathrm{mg} / 100 \mathrm{ml}$. Creatinine: $1.0 \mu \mathrm{mol} / 1 \approx 0.01 \mathrm{mg} / 100 \mathrm{ml}$. PO, $: 1.0 \mathrm{mmol} / 1$ $\approx 9.5 \mathrm{mg} / 100 \mathrm{ml}$

Statistical methods used were the Mann-Whitney test for unpaired samples, Spearman's rank correlation coefficient test, and the Wilcoxon test.

\section{Results}

The table gives the relevant clinical and biochemical details of the population studied. Patients with hypercalcaemia of malignancy had uniformly undetectable serum concentrations of parathyroid hormone, whereas in normocalcaemic patients values varied from undetectable to concentrations within the normal range. Serum creatinine concentrations were comparable in hypercalcaemic and normocalcaemic subjects. Tumours were mostly breast carcinomas in normocalcaemic patients and bronchial carcinomas in patients with hypercalcaemia.

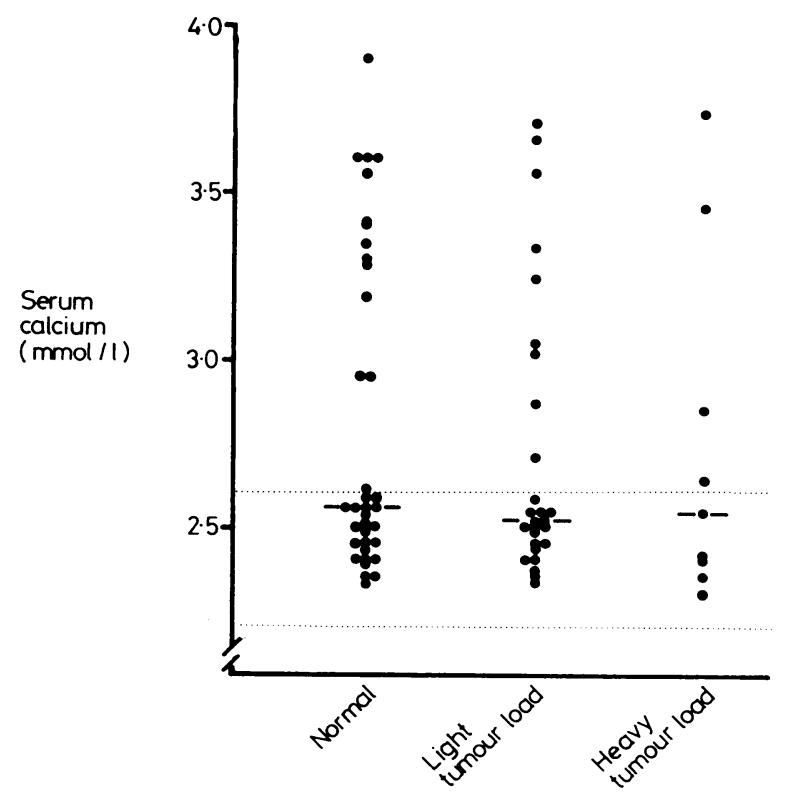

FIG 1-Serum calcium values in patients with malignancy. Dotted zone indicates normal range. Bars are medians.

Conversion: SI to traditional units-Calcium : $1.0 \mathrm{mmol} / 1 \approx 4.0$ $\mathrm{mg} / 100 \mathrm{ml}$.

In six normocalcaemic patients with abnormalities of doubtful relevance in the bone scan (non-diagnostic), biochemical values correlated most closely with those of patients with a normal scan. These subjects and one with hypercalcacmia and a non-diagnostic scan (who was later found to have no evidence of bone metastases at necropsy) were excluded from further study.

Analysis of the serum calcium concentrations in relation to the bone scan appearances of the remaining 74 patients showed no statistically significant association with the presence or extent of metastatic bone disease (fig 1). In all subsequent analyses patients were further subdivided on the basis of adjusted serum calcium concentrations into normocalcaemic $(<2.7 \mathrm{mmol} / 1 \quad<10.8 \mathrm{mg} /$ $100 \mathrm{ml})$ ) and hypercalcaemic $(\geqslant 2 \cdot 7 \mathrm{mmol} / \mathrm{l})$. Figure 2 shows the relation between filtered load of calcium (as judged by urinary $\mathrm{Ca}: \mathrm{Cr}$ ), and bone scan appearances in the hypercalcaemic and normocalcaemic subjects. Urinary $\mathrm{Ca}: \mathrm{Cr}$ values were significantly higher in the hypercalcaemic group for any given category of metastatic bone disease $(\mathrm{p}<0.001)$. Although urinary $\mathrm{Ca}: \mathrm{Cr}$ values tended to

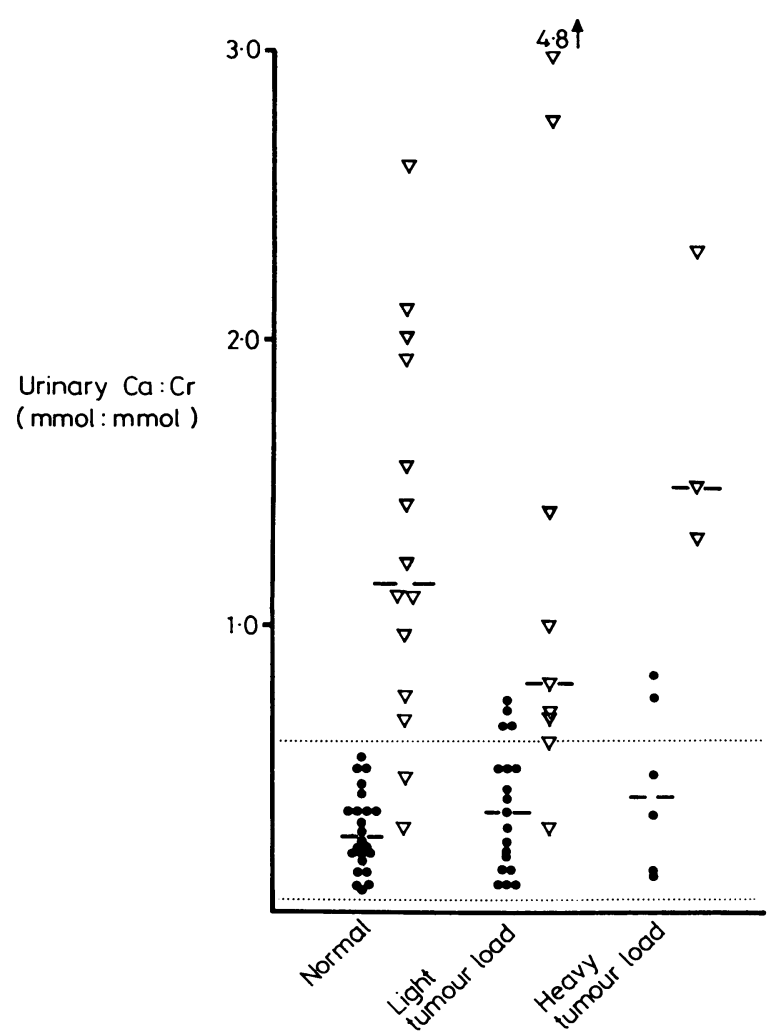

FIG 2-Urinary calcium excretion in patients with malignancy expressed as molar ratio of calcium to creatinine $(\mathrm{Ca}: \mathrm{Cr})$. Dotted zone indicates normal range. Bars are medians.

Normocalcaemic. $\nabla$ Hypercalcaemic.

Conversion: SI to traditional units-Calcium: $1.0 \mathrm{mmol} \approx$ $40 \cdot 0 \mathrm{mg}$. Creatinine: $1 \cdot 0 \mathrm{mmol} \approx 0 \cdot 1 \mathrm{~g}$.

rise in normocalcaemic patients with increasing metastatic bone disease, there was no statistically significant correlation between urinary $\mathrm{Ca}: \mathrm{Cr}$ values and extent of metastatic disease in either normocalcaemic or hypercalcaemic subjects.

Figure 3 gives a similar comparison between $\mathrm{OHP}: \mathrm{Cr}$ values and extent of metastatic disease seen in the bone scans. In normocalcaemic patients urinary OHP:Cr values were significantly raised in the presence of metastatic bone disease $(p<0.01)$. While the median $\mathrm{OHP}: \mathrm{Cr}$ value was lowest in those subjects with a normal bone scan and rose with the extent of metastatic bone disease, there was a considerable overlap among the three bone scan categories. In 


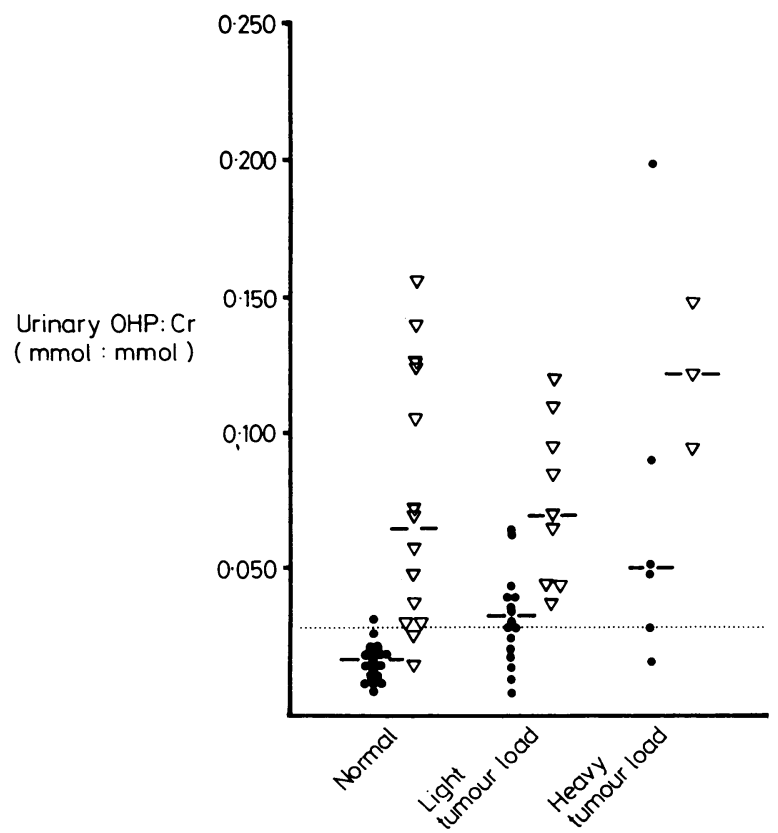

FIG 3-Urinary hydroxyproline excretion in patients with malignancy expressed as molar ratio of hydroxyproline to creatinine (OHP:Cr). Dotted zone indicates normal range. Bars are medians. Normocalcaemic. $\nabla$ Hypercalcaemic.

Conversion: SI to traditional units-Hydroxyproline: $1.0 \mathrm{mmol}$ $\approx 130.0 \mathrm{mg}$. Creatinine: $1.0 \mathrm{mmol} \approx 0.1 \mathrm{~g}$.

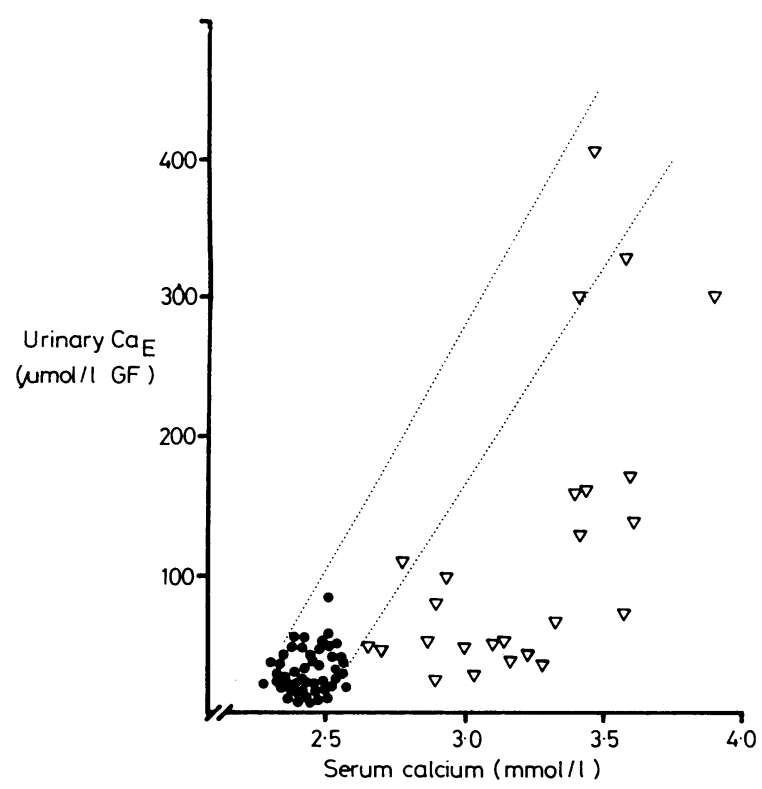

FIG 4-Urinary calcium excretion $\left(\mathrm{Ca}_{\mathrm{E}}\right)$ and serum calcium concentrations in patients with malignancy. $\left(\mathrm{Ca}_{\mathrm{E}}\right.$ calculated as molar ratio of $\mathrm{Ca}: \mathrm{Cr}$ multiplied by serum creatinine value and expressed as $\mu \mathrm{mol} / 1$ of glomerular filtrate $(\mathrm{GF})$ ). Dotted zone indicates normal range. Normocalcaemic. $\nabla$ Hypercalcaemic.

Conversion: SI to traditional units- $\mathrm{Ca}_{\mathrm{E}}: 1.0 \mu \mathrm{mol} / 1 \mathrm{GF} \approx 4.0 \mathrm{mg}$ / $100 \mathrm{ml} \mathrm{GF}$. Calcium $1.0 \mathrm{mmol} / 1 \approx 4.0 \mathrm{mg} / 100 \mathrm{ml}$.

hypercalcaemic patients urinary OHP:Cr values were much higher than in normocalcaemic patients for any given category of metastatic disease $(p<0.001)$ and no positive correlation was observed between the extent of metastatic disease and the urinary OHP:Cr value. Although numbers were small in the group categorised as heavy tumour load, no positive correlation was observed in normocalcaemic patients between urinary OHP:Cr values and serum calcium concentration $(r=0.203$; NS) or between $\mathrm{OHP}: \mathrm{Cr}$ and $\mathrm{Ca}: \mathrm{Cr}$ values $(r=0.084$; NS). In hyperculcaemic patients, however, values of urinary $\mathrm{Ca}: \mathrm{Cr}$ and $\mathrm{OHP}: \mathrm{Cr}$ were positively correlated $(r=0.422$; $\mathrm{p}<0.05)$, although urinary $\mathrm{OHP}: \mathrm{Cr}$ and serum calcium values were not $(r=0.295$; NS).

Figure 4 compares renal calcium handling in both hypercalcaemic and normocalcaemic subjects with malignancy in terms of the "normal" relation between the amount of calcium excreted and the serum calcium concentration, as originally defined by Peacock et $a l^{13}$ and later confirmed by us. ${ }^{9}$ In hypercalcaemic patients, both with and without bone metastases, urinary $\mathrm{Ca}_{\mathrm{E}}$ and serum calcium (adjusted) values generally fell to the right of the expected normal, reflecting increased renal tubular reabsorption of calcium. Conversely, urinary $\mathrm{Ca}_{\mathrm{E}}$ and serum calcium values in normocalcaemic subjects (also both with and without bone metastases) lay within the normal range, reflecting normal values of renal tubular reabsorption.

In normocalcaemic patients $\mathrm{TmPO}_{4}$ values lay within the normal range in most cases (fig 5). While values tended to rise progressively with the category of tumour load, the differences were not statistically significant. In hypercalcaemic patients $\mathrm{TmPO}_{4}$ values were significantly lower $(p<0.001)$ and did not correlate with the extent of bone metastases. In the study group as a whole there were significant inverse correlations between $\mathrm{TmPO}_{4}$ and urinary $\mathrm{OHP}: \mathrm{Cr}$ values $(r=-0.408 ; p<0.001), \mathrm{TmPO}_{4}$ and urinary $\mathrm{Ca}: \mathrm{Cr}$ values $(r=$ $-0.467 ; \mathrm{p}<0.001$ ), and $\mathrm{TmPO}_{4}$ and serum calcium concentrations $(\mathrm{r}=-0.563 ; \mathrm{p}<0.001)$.

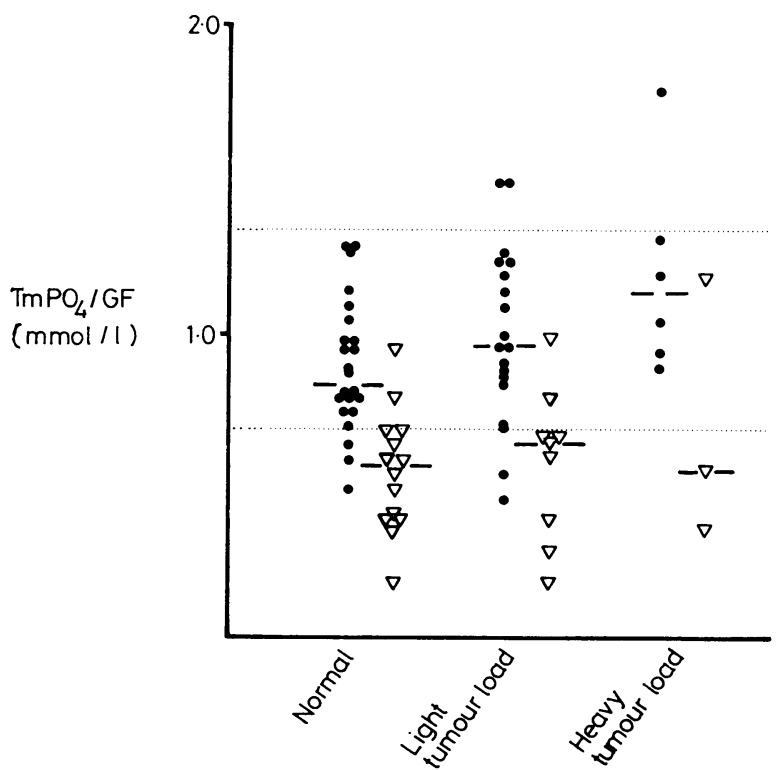

FIG 5-Renal phosphate threshold expressed as maximum tubular excretion of phosphate ( $\mathrm{TmPO}$ ) in $\mathrm{mmol}$ per litre of glomerular filtrate (GF). Dotted zone indicates normal range. Bars are medians. Normocalcaemic. $\nabla$ Hypercalcaemic. Conversion: $S I$ to traditional units $-\mathrm{PO}_{4}: 1 \cdot 0 \mathrm{mmol} / 1 \approx 9 \cdot 5 \mathrm{mg}$ / $100 \mathrm{ml}$.

\section{Discussion}

In patients with malignancy the detection of skeletal metastases is conventionally thought to provide reason enough for hypercalcaemia without the need to look for a humoral component. ${ }^{4}$ As bone metastases occur commonly in cancer, hypercalcaemia in these patients is most frequently regarded as having a "metastatic" rather than humoral aetiology. ${ }^{414}$

Nevertheless, in clinical studies a poor correlation has been observed between serum calcium values and radiological extent of metastatic disease. ${ }^{1516}$ Hitherto this discrepancy has been explained on the basis that standard radiological techniques are not sensitive enough to detect skeletal metastases. ${ }^{17}$ The bone scan-which reflects skeletal metabolic activity rather than anatomical change-is an extremely sensitive means of detecting metastases and is recognised as superior to radiology in this respect. ${ }^{1819}$ Accordingly, we used the radionuclide bone scan as the means of skeletal imaging. 
As in a previous but retrospective study $^{8}$ we found no positive correlation between extent of metastatic disease seen in the bone scan and the serum calcium concentration in patients with malignancy (fig 1). When renal calcium handling was examined, however, the following pattern emerged (fig 4): in hypercalcaemic patients after rehydration, urinary $\mathrm{Ca}_{\mathrm{E}}$ and serum calcium values generally fell to the right of expected normal, reflecting increased renal tubular reabsorption of calcium. Conversely, in normocalcaemic patients these values fell within the normal range, reflecting a "normal" rate of urinary calcium excretion. This suggests that in most cases the hypercalcaemia may have been partly explained by a humoral mediator with a "parathyroid-hormone-like" effect on renal tubular calcium reabsorption. ${ }^{9}$

In the fasting state urinary $\mathrm{Ca}: \mathrm{Cr}$ and $\mathrm{OHP}: \mathrm{Cr}$ values may be assumed to be a reasonably accurate means by which to assess bone resorption. ${ }^{11}$ In normocalcaemic patients we found that both OHP:Cr and $\mathrm{Ca}: \mathrm{Cr}$ values were much lower than in their hypercalcaemic counterparts for any given severity of metastatic disease detected by the bone scan. Furthermore, in hypercalcaemic patients no correlation was observed between the extent of metastatic disease seen in the bone scan and the urinary $\mathrm{OHP}: \mathrm{Cr}$ or $\mathrm{Ca}: \mathrm{Cr}$ value. This may indicate that in hypercalcaemia of malignancy bone resorption largely occurs on a systemic, humorally mediated basis rather than as the result of focal bone destruction by metastatic disease. Although $\mathrm{OHP}: \mathrm{Cr}$ and $\mathrm{Ca}: \mathrm{Cr}$ values were raised in normocalcaemic patients with metastatic disease, they did not reach the order of magnitude associated with hypercalcaemia, even in patients with a heavy skeletal tumour load (figs 2 and 3 ).

Other workers have considered that a reduced renal phosphate threshold $\left(\mathrm{TmPO}_{4}\right)$ is a useful biochemical marker in identifying a humoral mechanism of hypercalcaemia in patients with malignancy. ${ }^{5}{ }^{20}$ In our study also $\mathrm{TmPO}_{4}$ values were noticeably depressed in most of the hypercalcaemic patients, and in the study group as a whole we observed significant inverse correlations between $\mathrm{TmPO}_{4}$ and urinary $\mathrm{OHP}: \mathrm{Cr}$ values, $\mathrm{TmPO}_{4}$ and urinary $\mathrm{Ca}: \mathrm{Cr}$ values, and $\mathrm{TmPO}_{4}$ and serum calcium concentrations. This supports the concept that hypercalcaemia in patients with malignancy is caused by the action of a single humoral mediator with effects both on bone and on the renal tubule. 457920

Interestingly, $\mathrm{Ca}_{\mathrm{E}}$ and the serum calcium concentration fell within the normal range in three of our four hypercalcaemic patients with breast carcinoma, indicating that in these tumours the principle cause of hypercalcaemia may be increased filtered calcium load in the absence of an alteration in renal tubular reabsorption of calcium. None the less, the extent of metastatic disease as seen in the bone scans of these four patients failed to correlate with either urinary $\mathrm{OHP}: \mathrm{Cr}, \mathrm{Ca}: \mathrm{Cr}$ or serum calcium values (not shown). While a false negative bone scan may occur in some cases-for example, in widespread bone marrow infiltration-we should expect to find associated haematological abnormalities, such as a leucoerythroblastic peripheral blood film. No such abnormalities were noted in this study, however, which makes this pattern of disease less likely. Assuming the bone scan to be accurate, therefore, it may be postulated that hypercalcaemia in these patients was largely caused by a systemic, humorally mediated osteolytic process rather than as the result of focal bone destruction by metastatic disease.

In conclusion, this prospective study of patients with malignancy has shown that bone resorption from metastatic disease of the skeleton is generally of insufficient magnitude to account for the occurrence of hypercalcaemia. Although skeletal metastases were present in about half of the patients who developed hypercalcaemia, bone resorption in these subjects was greatly increased and disproportionate to the extent of metastatic disease seen in the bone scans. Furthermore, a reduced renal phosphate threshold and increased renal tubular calcium reabsorption were generally observed in hypercalcaemic patients when compared with their normocalcaemic counterparts. This suggests that in most cases hypercalcaemia of malignancy may be caused by the release of a humoral factor by tumour tissue which exhibits parathyroidhormone-like activity with respect both to bone resorption and to the renal tubular reabsorption of calcium and phosphate. From our observations it may be postulated that the putative humoral mediator in malignancy predisposes to hypercalcaemia both by stimulating generalised osteolysis and in most cases, also by impairing the renal excretion of the resultant increase in filtered calcium load. While hypercalcaemia may undoubtedly arise in some cases as the result of extensive bone destruction by metastases alone, our data suggest that this is the exception rather than the rule in the tumours studied.

We thank Dr R A Cowan and A Jenkins for the parathyroid hormone and hydroxyproline assays, Ms Carol Wilson and Ms Elaine Duncan for secretarial help, and the physicians and surgeons of Glasgow Royal Infirmary for allowing us to study patients under their care.

\section{References}

1 Coomes RC, Ward MK, Greenberg PB, et al. Calcium metabolism in cancer. Cancer 1976;38:2111-20.

2 Besarb A, Caro JF. Mechanisms of hypercalcemia in malignancy. Cancer $1978 ; 41: 2276-85$.

${ }^{3}$ Hosking DJ, Cowley A, Bucknall CA. Rehydration in the treatment of severe hypercalcaemia. $Q \mathcal{F}$ Med $1981 ; 200: 473-87$.

4undy GR, Martin TJ. The hypercalcemia of malignancy: pathogenesis and management. Metabolism 1982;31:1247-77.

${ }^{5}$ Stewart AF, Horst R, Deftos LJ, Cadman EC, Lang R, Broadus AE. Biochemical evaluation of patients with cancer-associated hypercalcemia. $N$ Engl f Med 1980;303:1377-83.

6 Omenn GS, Roth SI, Baker WH. Hyperparathyroidism associated with malignant tumors of non parathyroid origin. Cancer 1969;24:1004-12.

${ }^{7}$ Lafferty FW. Pseudohyperparathyroidism. Medicine 1966;45:247-60.

${ }^{8}$ Ralston S, Fogelman I, Gardiner MD, Boyle IT. Hypercalcaemia and metastatic bone disease: is there a causal link. Lancet $1982 ; \mathrm{i}: 903-5$.

${ }^{9}$ Ralston SH, Fogelman I, Gardiner MD, Dryburgh FJ, Boyle IT. Hypercalcaemia of malignancy: evidence for a non-parathyroid humoral agent with an effect on renal handling of calcium. Clin Sci (in press).

10 Gardiner MD, Dryburgh FJ, Fyffe JA, Jenkins AS. Predictive value of derived calcium figures based on the measurement of ionised calcium. Ann Clin Biochem 1981 ; 18:106-9.

11 Nordin BEC, ed. Calcium, phosphate and magnesium metabolism. Edinburgh : Churchill Livingstone, 1976.

$12 \mathrm{Bijvoet}$ OLM. Indices for the measurement of the renal handling of phosphate. In: Massry SG, Fleish H, eds. Renal handling of phosphate. New York: Plenum, 1980:1-37.

13 Peacock M, Robertson WG, Nordin BEC. Relation between serum and urinary calcium with particular reference to parathyroid activity. Lancet 1969;i:384-7.

${ }_{14}$ Myers WPL. Hypercalcemia in neoplastic disease. Ann Surg 1960;80: 308-18.

15 Gardiner B. The relation between serum calcium and tumor metastases Surg Gynecol Obstet 1969;128:369-74.

16 Campbell FC, Blamey RW, Woolfson AMJ, Elston CW, Hosking DJ Calcium excretion in metastatic breast cancer. Brf Surg 1983;70:202-4.

17 Bachman AL, Sproul EE. Correlation of radiographic and autopsy findings in metastases of the spine. Bull NY Acad Med 1955;31:146-8.

18 Roberts JG, Gravelle IH, Baum M, Bligh AS, Leach KG, Hughes LE. Evaluation of radiography and isotope scintigraphy for detecting skeletal metastases in breast carcinoma. Lancet $1976 ; \mathrm{i}: 273$.

19 Citrin DL, Bessent RG, Greig WR, McKellar NJ, Furnival C, Blumgart LH. The application of $99 \mathrm{~m} \mathrm{Tc}$ phosphate bone scan to the study of breast cancer. Br $\mathcal{F}$ Surg 1975;62:201.

20 Sleeboom HP, Van Oosteram AT, Bijvoet OLM, Gleed JH, O'Riordan JLU. Comparison of intravenous (3-amino-1-hydroxypropylidene)-1-1biphosphonate and volume repletion in tumour induced hypercalcaemia. Lancet 1983;ii :239-43.

(Accepted 16 February 1984) 